\title{
Fatigue behaviour of an epoxy adhesive under mixed-mode conditions
}

\author{
Mário Rui Oliveira Cunha ${ }^{1}$ \\ Ricardo João Camilo Carbas ${ }^{1,2}$ \\ Eduardo André Sousa Marques ${ }^{1}$ \\ Alireza Akhavan-Safar ${ }^{1}$ \\ Lucas Filipe Martins da Silva ${ }^{1 *}$ (1)
}

\begin{abstract}
The aim of this study is to characterize the fatigue behaviour of a structural epoxy adhesive loaded in mixedmode conditions. To this effect, several fracture tests were carried out: Double Cantilever Beam (DCB) for pure mode I, End Notched Flexure (ENF) for pure mode II, and mixed-mode testing, using an apparatus that enables the application of mixed-mode loadings to an adhesive and with high strength steel adherends. The fracture envelope was calculated using experimental data and it was found to be compatible with a quadratic criterion. A novel quadratic law criterion was developed to fit the envelope. The fatigue behaviour was studied recurring to fatigue crack growth curves for the same types of loads studied in the quasi-static tests. A relationship between mixed-mode phase angle and the Paris law slope was found, where the existence of mode II loads was found to delay crack propagation. By performing fatigue tests at $60 \%$ and $80 \%$ of the maximum load, it was noticed that increasing the load leads to the increase of the threshold energy release rate values.
\end{abstract}

Keywords: Epoxy adhesive; Fatigue loads; Mixed-mode tests; Fracture envelope.

\section{Introduction}

The industrial use of structural adhesives has increased significantly in the transportation sector in the last few decades, driven in part by the greater adoption of composite materials and serving as a replacement for conventional joining methods. This increased usage is explained by the potential adhesives offer for weight reduction and the improved mechanical performance of adhesive joints. When compared to other traditional joining methods, the use of adhesives leads to joints with more uniform stress distribution and reduced joint stiffness, which allows for better vibration damping and thus improved fatigue behaviour. These advantages are particularly important for the automotive industry as they provide a path for improving fuel economy and reducing emissions through a lighter, yet strong vehicle Within this context, it has become important to properly characterize adhesives under loadings that replicate the actual service conditions. The adhesives used in structural applications are designed to operate under shear loads, as these distribute the acting stresses over a larger area. However, this often does not match actual service conditions, since in practice the loads applied are complex combinations of mode I (traction) and mode II (shear). Another problem affecting adhesives, and bonded components in general, is fatigue. Sometimes materials fail without reaching critical stresses because of the damage accumulated by multiple small loads throughout the service time and adhesives, although less sensitive than other materials, are no exception. Fatigue behaviour under mode I and II is well covered in the literature, but fatigue under mixed-mode is still a lightly explored subject. By studying how an adhesive behaves under a fatigue loading and mixedmode conditions, it is possible to make better predictions concerning the behaviour of the adhesive in conditions closer to those encountered under service, being the objective of this paper to describe how the fatigue behaviour of an adhesive changes as a function of the mixed-mode phase angle [1].

Many different mixed-mode tests are described in the literature, such as Cracked Lap Shear [2], Arcan [3] or Modified Arcan [4], Single Leg Bending (SLB) [5], Asymmetric Double Cantilever Beam (ADCB) [6], Asymmetric Tapered Double Cantilever Beam (ATDCB) [7]; but most of these require a specific specimen and provide fracture toughness results for only one mixed-mode combination. The Mixed Mode Bending (MMB) [8] test is the only standard test for mixed mode toughness. This test was first proposed and developed for composites and is not directly applicable for stiffer aluminium or steel adherends [9]. To overcome the existing difficulties for measuring mixed-mode fracture toughness, a novel apparatus was developed by the

${ }^{I}$ Departamento de Engenharia Mecânica, Faculdade de Engenharia - FEUP, Universidade do Porto, Porto, Portugal.

${ }^{2}$ Instituto de Ciência e Inovação em Engenharia Mecânica e Engenharia Industrial - INEGI, Porto, Portugal.

*Corresponding author: lucas@fe.up.pt

2176-1523 (C) 2021. Cunha et al. Published by ABM. This is an Open Access article distributed under the terms of the Creative Commons Attribution License, which permits unrestricted use, distribution, and reproduction in any medium, provided the original work is properly cited. 
authors [10]. The proposed apparatus is an evolution of the existent Spelt loading jig [11], with the main difference being that direct crack length measurement is not needed. Instead, two linear variable differential transformers (LVDT) are used to measure the deflection of the bonded beams and the location of the crack is estimated by using a set of equations derived from beam theory, a technique known as the Compliance Based Beam Method (CBBM). Another key difference is that the specimen is located fully inside of the structure, reducing the overall dimensions of the test setup and increasing the stiffness [12]. The specimens used in the apparatus for mixed-mode are similar to the ones used in the DCB and ENF tests, making it possible to use only one kind of specimen geometry for all tests.

Fracture envelopes are graphical representations, where the strain energy release rate $G$, is plotted in an x-y axis. The mode I and mode II values correspond to the $y$ and $x$ axis, respectively, and the mixed mode fracture energy is displayed in the quadrant as a two-component point, composed by $x$ coordinate correspondent to the mode II and $y$ coordinate correspondent of mode I [13]. The fracture envelope can be generated using data from different mixed-mode tests. Stamoulis et al. [14] used the MMB test, da Silva et al. [13] used SLB, ADCB and ATDCB tests and Costa et al. [10] used the apparatus employed in the present work.

By plotting the experimental mixed-mode values in an $x-y$ axis, it is sometimes possible to detect a trend for the values obtained. There are essentially two criterions that can be applied using the critical fracture energy for mode I, $G_{I c}$, and for mode II, $G_{I I c}$ : the power law [15], and the Benzeggagh \& Kenane law [16]. The power law can fit virtually any curve that does not describe an increase near mode I while the Benzeggagh \& Kenane criterion is suitable to fit envelopes that display an increase near mode I. The main disadvantage of Benzeggagh \& Kenane criterion is that it implies that the total energy release rate is the sum of each mode component, which is not always valid. This criterion is especially useful when performing MMB tests, where the modal ratio depends on the geometry of the test setup.

Studying the long-term durability of an adhesive is of great importance for practical applications as fatigue damage is responsible for $80 \%$ of failures in service. Fatigue damage is defined as a loss of properties over time due to alternating stresses. Thus, the loads that cause fatigue failure are smaller than those required to cause quasi-static failure [17]. When it comes to fatigue performance, adhesive joints are generally better than traditional fastening joints due to flexibility and thus damping capabilities of adhesives, which absorb a part of the vibrations that would otherwise be transferred to the structure. In some cases, adhesive layers can also be combined with conventional fastening joints to improve mechanical behaviour [1]. Fatigue induced crack growth is very complex in polymeric materials because many factors influence crack initiation and propagation, such as environmental conditions like humidity and temperature, porosities, lack of homogeneity and insufficient cure.
These are all key factors in the fatigue damage process, increasing the difficulty of characterizing the crack growth behaviour of adhesive joints [18].

Structural joints, much like all materials, possess defects that may become pathways for crack propagation if a certain load is applied. The fracture mechanics approach for predicting fatigue behaviour is called Fatigue Crack Growth (FCG). This theory assumes the presence of a small crack on a structure under cyclic loading and analyses its crack propagation $[1,18]$. FCG rate, $d a / d N$, can be plotted as a function of the strain energy release rate $G$ to create FCG curves. Studies applied to adhesives show that these curves followed the same pattern seen in metals and polymers [19]. Three regions can be distinguished in the FCG graph: a first phase where the crack begins called the subcritical region, a second phase where crack propagation is stable, and a third phase where rapid crack propagation occurs, which is very unstable. It is important to note that FCG theory only applies to the second phase, meaning that the power law relationship between strain energy release rate $G$, and crack growth rate $d a / d N$, exists in this phase only $[17,18]$. The crack growth rate, is calculated using either the secant method or the incremental polynomial method, as recommended in the ASTM E647 standard [20]. The secant method was chosen since it is the most appropriate approach in crack-opening displacement tests [21].

The objective of this this study was to assess the Paris Law (PL) curves as a function of mixed-mode angle for a structural epoxy adhesive. Strength and fracture tests under quasi-static conditions were performed to define the parameters for fracture tests under fatigue conditions. Fracture energies were compiled in a fracture envelope.

\section{Experimental details}

A one component, epoxy structural adhesive, composed mainly by Epichlorohydrin-4,4'-isopropylidene diphenol resin, was used in this work. Complete cure of the adhesive was achieved by subjecting the adhesive to a heating stage of $175^{\circ} \mathrm{C}$ for 25 minutes.

\subsection{Tensile tests}

Bulk tensile tests were carried out by applying a constant displacement rate to a dog bone type specimen, machined from a rectangular bulk adhesive plate. The adhesive plates were manufactured according the NF T 76-142 French standard [22] which uses hydrostatic pressure to ensure defect free specimens. Cured adhesive plates were machined to a dog bone shape according to ASTM D-638 [23].

Figure 1 shows the specimen geometry used to determine the tensile behaviour of the adhesive. The displacement rate was $1 \mathrm{~mm} / \mathrm{min}$, and the strain was measured with the use of an extensometer. 


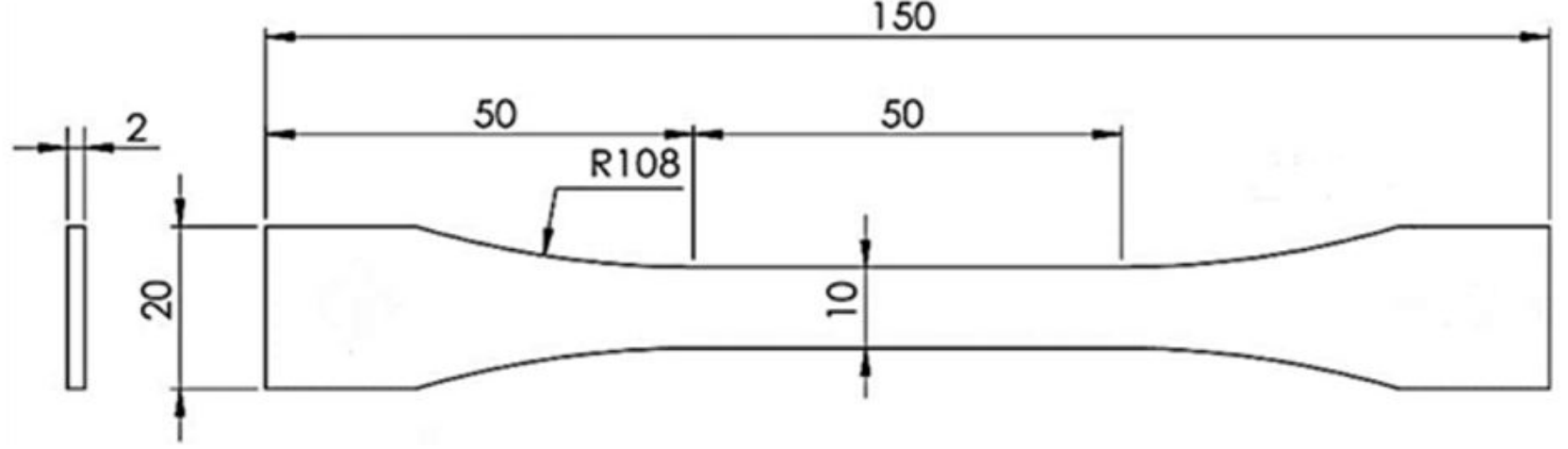

Figure 1. Specimens machined from bulk sheet (dimensions in $\mathrm{mm}$ ).
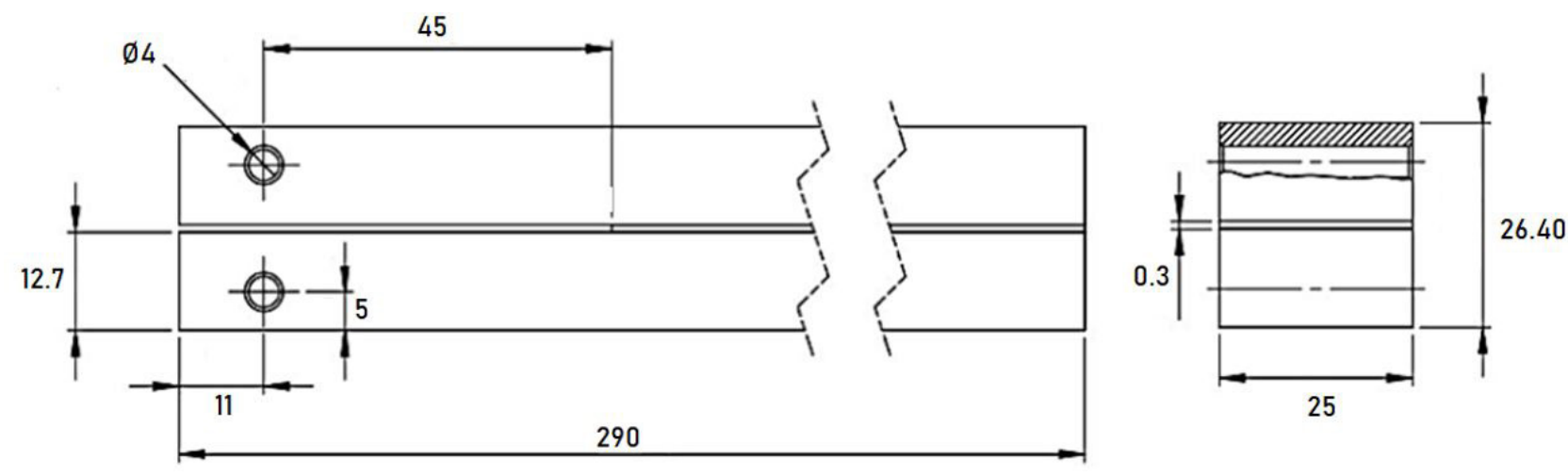

Figure 2. Specimens' geometry, adapted from [22] (dimensions in mm).

\subsection{Fracture tests}

The specimens used for all fracture tests followed the ASTM D-3433 standard [20] and the adherends material used was a high strength DIN 40CrMnMo7 steel. The same specimens' geometry was used for DCB tests, it was also used for ENF tests and mixed-mode tests as the mixed mode testing apparatus was designed to be compatible with it. The specimen geometry is presented in Figure 2.

\subsubsection{Pure mode I and II tests}

DCB tests were completed to assess the adhesive's fracture behaviour under pure mode I, allowing for the determination of the critical energy release rate $G_{I c}$. ENF tests were performed to define adhesive fracture behaviour in mode II, determining critical energy release rate for pure mode II $G_{I I c}$. A constant displacement rate of $0.2 \mathrm{~mm} / \mathrm{min}$ was used in all tests, independently of loading mode. CBBM was used to obtain the R-curves.

\subsubsection{Mixed-mode fracture tests}

Using the mixed-mode apparatus displayed in Figure 3, mixed-mode tests were performed $[10,12]$. The tested mixedmode phase angles were $\varphi=22.2^{\circ}$ and $\varphi=56.6^{\circ}$.

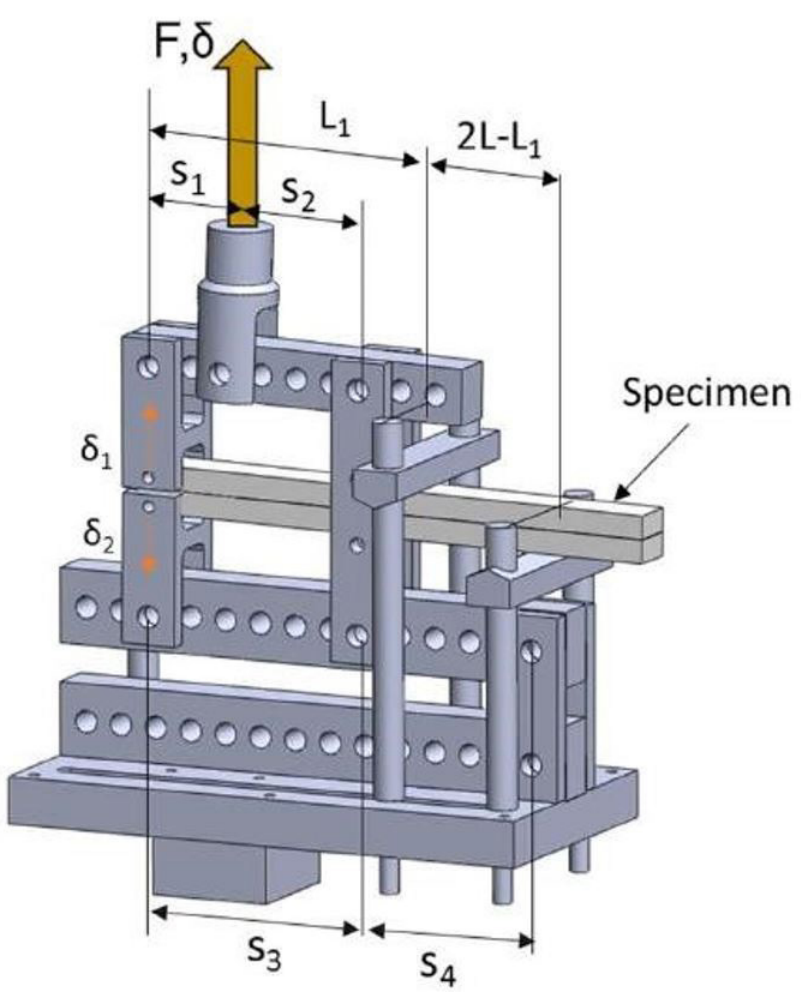

Figure 3. 3D scheme of the apparatus. 
For the tested angles, the beam lengths were set as described in Table 1.

The displacement rate of $0.2 \mathrm{~mm} / \mathrm{min}$ was maintained for the mixed-mode tests. CBBM was used to obtain two R-curves (one for mode I and one for mode II). Two LVDT were used to determine $\delta_{1}$ and $\delta_{2}$. The use of two LVDTs allows for the separation of the displacements for each mixed mode, something that cannot be achieved by purely relying on the crosshead displacement of the testing machine

\subsection{Fatigue tests}

To characterize the adhesive fatigue fracture behaviour, tests were performed in the same conditions as those described for quasi-static testing. Namely, the DCB test for pure mode I, the ENF test for pure mode II and, mixed-mode apparatus testing for $\varphi=22.2^{\circ}$ and $\varphi=56.6^{\circ}$.

Fatigue tests were performed for load percentages of $60 \%$ and $80 \%$ of the maximum loads obtained in the quasistatic tests. A load ratio of 0.1 was used, meaning $P_{\text {mix }}$ is $10 \%$ of $P_{\max }$. The used frequency was $1 \mathrm{~Hz}$, the maximum possible using the available servo hydraulic testing equipment.

\section{Results and discussion}

\subsection{Tensile tests}

Tensile tests were performed to characterize the tensile properties of the bulk adhesive. Figure 4 shows a representative stress-strain curve.

Table 2 summarizes the results for bulk adhesive tensile properties.

Table 1. Apparatus configuration according to the mixed-mode phase angles $(\varphi)$ tested

\begin{tabular}{ccccccc}
\hline $\boldsymbol{\varphi}\left({ }^{\circ}\right)$ & $\mathbf{s}_{\mathbf{1}}(\mathbf{m m})$ & $\mathbf{s}_{\mathbf{2}}(\mathbf{m m})$ & $\mathbf{s}_{\mathbf{3}}(\mathbf{m m})$ & $\mathbf{s}_{\mathbf{4}}(\mathbf{m m})$ & $\begin{array}{c}\boldsymbol{L}_{\mathbf{1}} \\
(\mathbf{m m})\end{array}$ & $\begin{array}{c}\boldsymbol{2 L} \\
(\mathbf{m m})\end{array}$ \\
\hline 22.2 & 60 & 100 & 160 & -60 & 205 & 230 \\
56.6 & 60 & 80 & 140 & 80 & 180 & 230 \\
\hline
\end{tabular}

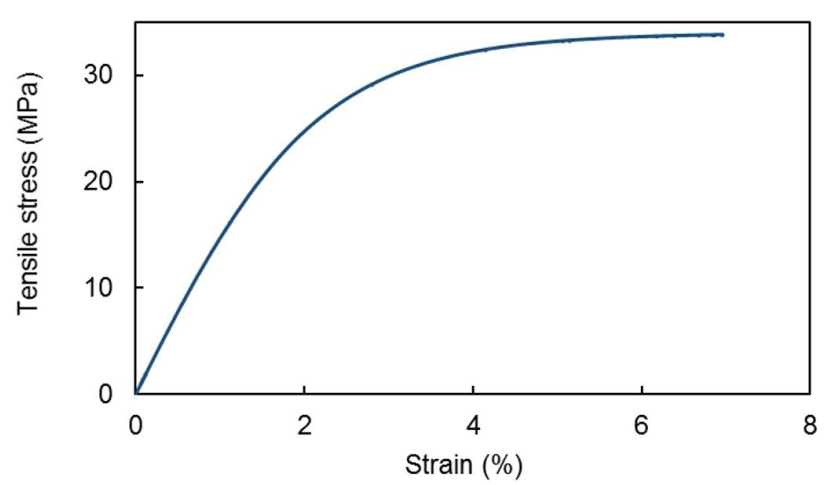

Figure 4. Typical stress-strain curve.

\subsection{Fracture tests}

\subsubsection{Pure mode I and II}

The DCB and ENF tests were performed under quasistatic conditions at a displacement rate of $0.2 \mathrm{~mm} / \mathrm{min}$ and the R-curves were determined from the load-displacement registered during the test using the CBBM. Table 3 summarizes the pure mode I and II critical energy release rates.

\subsubsection{Mixed-mode I+II $\left(\varphi=22.2^{\circ}\right)$}

Fracture energy under mixed-mode conditions was determined using the in-house developed apparatus. A mixedmode angle of $22.2^{\circ}$ presents a mixed-mode condition quite close to mode I, meaning that the applied load is mainly of this type with a small mode II contribution.

Table 4 shows the resulting energy release rates for the phase angle of $22.2^{\circ}$. The effective mixed-mode angle was also assessed using the obtained $G_{I}$ and $G_{I I}$ values, which in practice were higher than $22.2^{\circ}$ for every specimen. This might be due to the deviations in the positioning of the specimens in the apparatus since the optimal theoretical position is often difficult to precisely achieve in practice.

\subsubsection{Mixed-mode I+II $\left(\varphi=56.6^{\circ}\right)$}

Fracture energies at $\phi=56.6^{\circ}$ were calculated using the same methodology described for the phase angle $\phi=22.2^{\circ}$. To test this different mixed-mode phase angle only the arrangement of the beams in the apparatus was changed.

The fracture energy at $\phi=56.6^{\circ}$ result was within the expected values since both components were lower than the respective value obtained for the pure modes (DCB and ENF tests). With a phase angle of $56.6^{\circ}$, it is expected that both components contribute significantly to the total fracture energy, which was verified. Also, given that adhesives behave better with shear loads, it is normal that the mode II component is visibly higher. The resulting fracture energies

Table 2. Adhesive strength properties

\begin{tabular}{ccc}
\hline $\begin{array}{c}\text { Young's modulus } \\
(\mathbf{M P a})\end{array}$ & $\begin{array}{c}\text { Tensile strength } \\
(\mathbf{M P a})\end{array}$ & $\begin{array}{c}\text { Strain to failure } \\
(\%)\end{array}$ \\
\hline $1555 \pm 142$ & $33.85 \pm 0.07$ & $7.23 \pm 0.94$ \\
\hline
\end{tabular}

Table 3. Critical energy release rate for mode I

\begin{tabular}{cc}
\hline $\boldsymbol{G}_{I c}(\mathrm{~N} / \mathbf{m m})$ & $\boldsymbol{G}_{I I c}(\mathrm{~N} / \mathbf{m m})$ \\
\hline $1.89 \pm 0.10$ & $7.44 \pm 0.62$ \\
\hline
\end{tabular}

Table 4. Fracture energies for the mixed-mode angle, $\phi_{\text {apparatus }}=22.2^{\circ}$

\begin{tabular}{ccccc}
\hline $\begin{array}{c}\text { papparatus } \\
\left({ }^{\circ}\right)\end{array}$ & $\begin{array}{c}\boldsymbol{G}_{\boldsymbol{I}} \\
(\mathbf{N} / \mathbf{m m})\end{array}$ & $\begin{array}{c}\boldsymbol{G}_{\boldsymbol{I I}} \\
(\mathbf{N} / \mathbf{m m})\end{array}$ & $\begin{array}{c}\boldsymbol{G}_{T} \\
(\mathbf{N} / \mathbf{m m})\end{array}$ & $\begin{array}{c}\boldsymbol{\varphi}_{\text {effective }} \\
\left.\mathbf{(}^{\circ}\right)\end{array}$ \\
\hline 22.2 & $2.40 \pm 0.10$ & $0.69 \pm 0.09$ & $2.50 \pm 0.12$ & $28.11 \pm 0.99$ \\
\hline
\end{tabular}


are summarized in Table 5, where the mean values and respective standard deviations are shown.

\subsection{Fracture envelope}

An adhesive's critical energy release rate $G$, changes according to the mixed-mode phase angle $\phi$. As described before, adhesives perform better when loaded in shear as stresses are distributed over a larger area, meaning that the critical energy release rate in mode II is always higher than that obtained under mode I conditions. Studying the fracture envelope of an adhesive will provide information on how an adhesive will behave when loaded at any mixed-mode phase angle. The fracture envelope presented in Figure 5 combines information from both pure mode's fracture tests with information from the mixed-mode fracture tests obtained using the apparatus.

A quadratic criterion can be formulated to capture the increase near mode I, similar to what can be achieved with the Benzeggagh \& Kenane criterion, but with a different overall shape. Equation 1 shows the fundamental equation, which is an equation relating $\mathrm{G}_{\mathrm{I}}$ and $\mathrm{G}_{\mathrm{II}}$.

$$
\mathrm{G}_{\mathrm{I}}=\mathrm{AG}_{\mathrm{II}}{ }^{2}+\mathrm{BG}_{\mathrm{II}}+\mathrm{C}
$$

The scalar values $A, B$ and $C$ can be calculated as a function of $G_{I C}$ and $G_{I I C}$ by solving the boundary conditions presented in Figure 6.

To formulate the quadratic law three conditions are considered:

- I. implies that when $G_{I I}=0, G_{I}=G_{I C}$,

- II. implies that the derivative of $G_{I I}$ in the point of inflexion $P_{I N F}$ is zero,

- III. implies that when $G_{I I}=G_{I I C}, G_{I}=0$.

After simplifying, the set of equations in Equation 2 can be obtained.

Table 5. Fracture energies for the mixed-mode angle, $\phi_{\text {apparatus }}=56.6^{\circ}$

\begin{tabular}{ccccc}
\hline $\begin{array}{c}\text { papparatus } \\
\left({ }^{\circ}\right)\end{array}$ & $\begin{array}{c}\boldsymbol{G}_{\boldsymbol{I}} \\
(\mathbf{N} / \mathbf{m m})\end{array}$ & $\begin{array}{c}\boldsymbol{G}_{\boldsymbol{I}} \\
(\mathbf{N} / \mathbf{m m})\end{array}$ & $\begin{array}{c}\boldsymbol{G}_{T} \\
(\mathbf{N} / \mathbf{m m})\end{array}$ & $\begin{array}{c}\boldsymbol{\varphi}_{\text {effective }} \\
\left.\boldsymbol{(}^{\circ}\right)\end{array}$ \\
\hline 56.6 & $1.81 \pm 0.08$ & $5.70 \pm 0.08$ & $5.98 \pm 0.06$ & $60.60 \pm 0.70$ \\
\hline
\end{tabular}

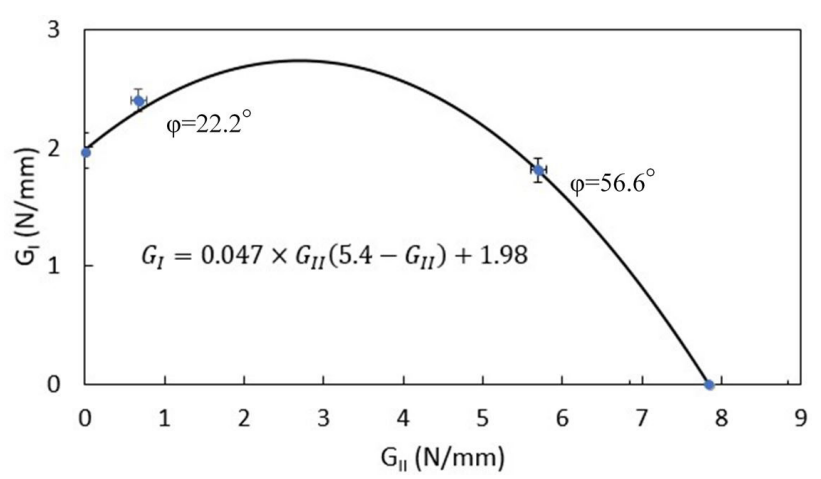

Figure 5. The obtained fracture envelope, using the quadratic criterion.

$$
\left\{\begin{array}{c}
\mathrm{C}=\mathrm{G}_{\mathrm{Ic}} \\
\mathrm{B}=-2 \mathrm{P}_{\text {inf }} \times \mathrm{A} \\
0=\mathrm{A} \times \mathrm{G}_{\mathrm{IIc}}{ }^{2}+\mathrm{B} \times \mathrm{G}_{\mathrm{IIc}}+\mathrm{C}
\end{array}\right.
$$

The simplified formulation is described in Equation 3.

$$
\mathrm{G}_{\mathrm{I}}=\frac{\mathrm{G}_{\text {Ic }} \times \mathrm{G}_{\text {II }}}{\mathrm{G}_{\text {IIc }}\left(\mathrm{G}_{\text {IIc }}-2 \mathrm{P}_{\text {inf }}\right)}\left(2 \mathrm{P}_{\text {inf }}-\mathrm{G}_{\text {II }}\right)+\mathrm{G}_{\text {Ic }}
$$

By adjusting the value for the point of inflection, which is the parameter in the quadratic law, it is possible to formulate an envelope. Figure 7 shows the influence of this parameter in the envelope shape.

Both fracture energy values obtained $\left(G_{I c}\right.$ and $\left.G_{I I C}\right)$ are within what is expected for epoxy-based adhesives [24]. Mode II fracture energies are generally higher than those for mode I, which was verified when comparing the results for the pure modes and when comparing both components obtained for $\phi=56.6^{\circ}$. The same did not happen for $\phi=22.2^{\circ}$ because the type of load for this angle was mainly mode I.

The results for $\phi=22.2^{\circ}$ were within the expected since this type of behaviour has already been seen in literature. According to the literature, a slight increase near mode I is sometimes visible [14,24], this behaviour was seen when testing for $\phi=22.2^{\circ}$. Costa et al. [24] studied three epoxy adhesives with different ductility were tested, where the most ductile adhesive exhibited the greatest increase near mode I, and the least ductile the smallest. Considering that the tested adhesive has ductile behaviour, the increase near mode I was expected.

The results for the mixed-mode phase angle of $56.6^{\circ}$ were within the expected, where both mode components
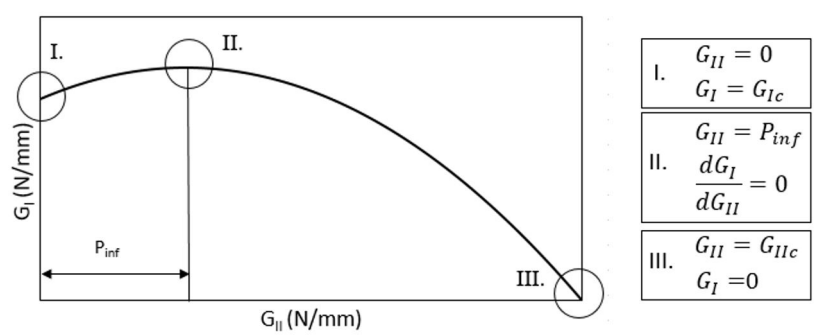

Figure 6. Boundary conditions used to formulate the quadratic law.

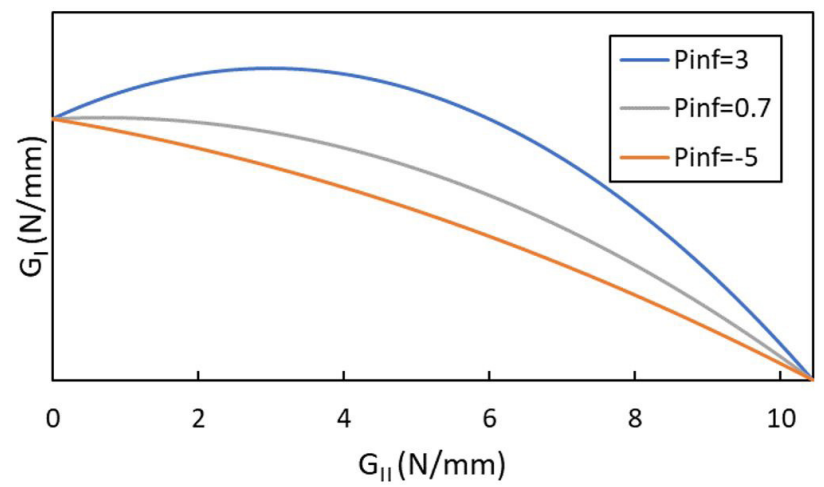

Figure 7. Quadratic law as function of the parameter $\mathrm{P}_{\text {inf }}$. 
reached fracture energies below the respective mode's critical fracture energy. The plotted envelope was obtained assuming a continuous evolution of the fracture energy its accuracy can be improved by testing more mixed-mode angles.

Figure 8 shows the different criterions applied to the obtained envelope. While the power law and the Benzeggagh \& Kenane criterion can fit one of the mixedmode values, the proposed quadratic law appears to be a better fit when considering all the values.

\subsection{Fatigue}

Fatigue tests were performed to assess the FCG behaviour. For the fatigue analysis, only the maximum loads were used because that is when the material is damaged.

\subsubsection{Mode I}

To test fatigue under mode I, the specimens were submitted to successive opening cycles at a given percentage of the static load. Initially, the applied fatigue load was $80 \%$ of the quasi-static failure load, sometimes resulting in tests that would fail under a small number of cycles (oligo-cyclic fatigue), because the load was too close to the static failure load. To make sure the FCG curve would be fully captured in the test, a load of $60 \%$ of the maximum quasi-static load was also tested. Ultimately, results were achieved for both tested load percentages. The resulting $80 \% \mathrm{FCG}$ curve is displayed in Figure 9. The $x$ axis of the fatigue crack growth curve represents the ratio between the maximum fracture toughness for the test, divided by the critical fracture toughness in this mode whily the $y$ axis corresponds to fatigue crack growth per cycle.

Figure 10 shows a comparison of the obtained PL parameters for both load levels ( $60 \%$ and $80 \%$ ).

Comparing the tests done at $60 \%$ and at $80 \%$ of the maximum load, it is visible that the PL slope (Figure 11a) displays a slight increase. In Figureb, it can be seen that the $C$ value has a high standard deviation. The high standard deviations because the FCG curve is exponential in nature, and even though some curves might be visually similar when plotted in a $\log -\log$ graph, the $C$ value might in fact differ substantially. The results for the cycles to failure are displayed in Figure 11c, where the effect of the load increase is expected because as the imposed load becomes much

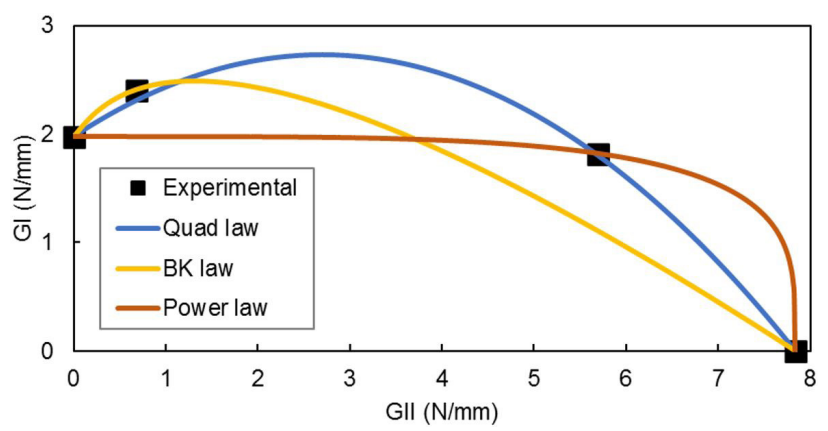

Figure 8. Multiple criterions applied to the fracture envelope.

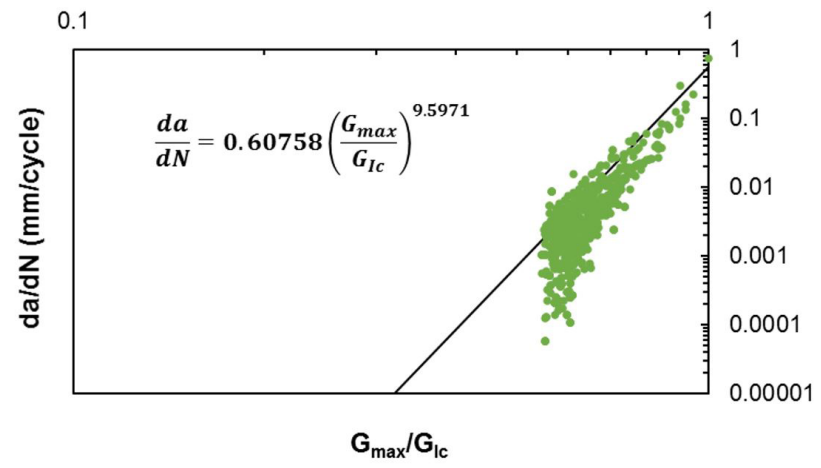

Figure 9. Representative DCB fatigue crack growth curves for $80 \%$ maximum load.

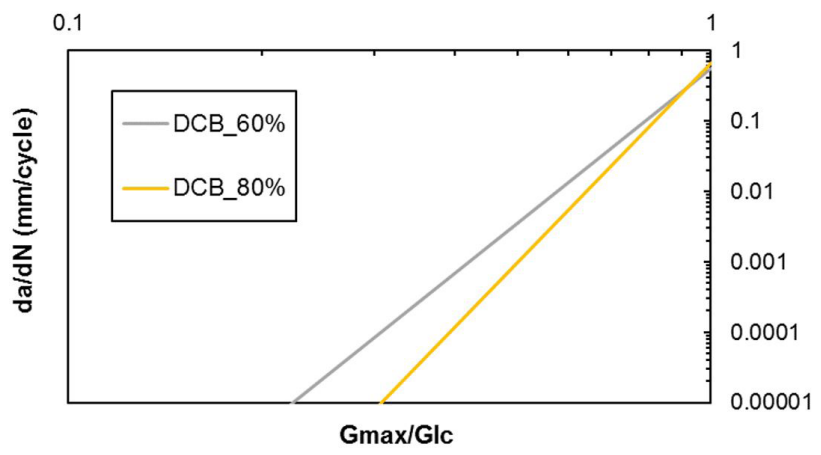

Figure 10. DCB Paris law trends plotted in the same graph. a)

PL slope, $m$

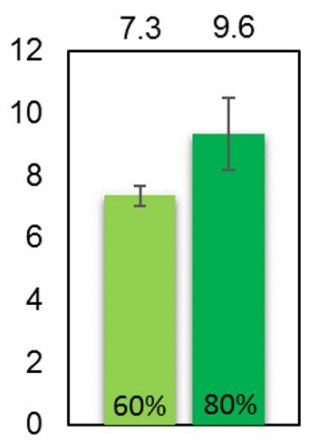

c)

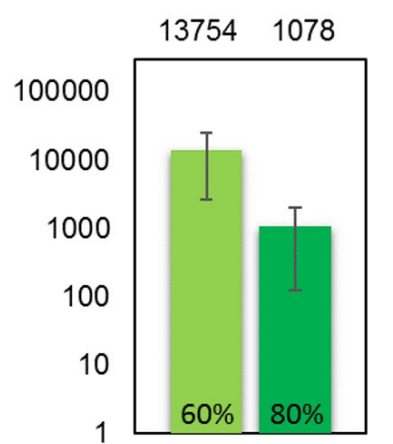

b) PL-intercept, $\mathrm{C}$

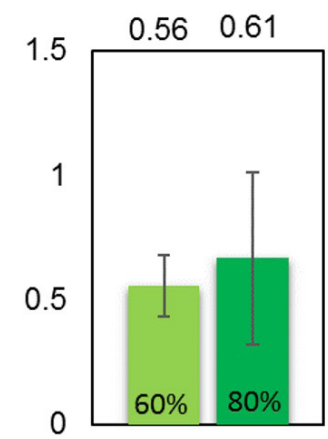

Figure 11. Fatigue results for mode I, DCB tests, (a) Paris law slope results, (b) Paris law y-intercept results, (c) cycles to failure results, (d) $G_{t h}$ results. 
lower than the static failure load, the specimen endures more cycles before failure. Figure $11 \mathrm{~d}$ displays the threshold energy release rate value that tends to increase when the load increases; this is expected given that $G$ is directly related to $P$. Azari et al. [25] studied threshold behaviour for different loads by changing the displacement ratio and obtained similar results.

The PL intercept, in Figure 11b, the cycles to failure, in Figure 11c, and the threshold energy release rate, in Figure $11 \mathrm{~d}$, are virtually the same. The PL slope is slightly lower for $60 \%$ compared to $80 \%$.

\subsubsection{Mode II}

To test the fatigue behaviour in mode II, ENF tests were performed using CBBM to deduce the energy release rate and the equivalent crack length values. The same test scheme used in mode I was followed for mode II tests regarding the load percentages applied. An example of FCG curve obtained for the ENF test at $80 \%$ of the maximum load is displayed in Figure 12.

After testing specimens from all conditions, similar FCG curves were obtained. Figure 13 shows the comparison of the obtained PL parameters for each condition.

Comparing the ENF tests done at $60 \%$ and at $80 \%$ of the maximum load, it can be seen that the PL slope was not significantly affected by the load level (Figure 14a). As seen in Figure 14b, the PL intercept, similarly to the DCB

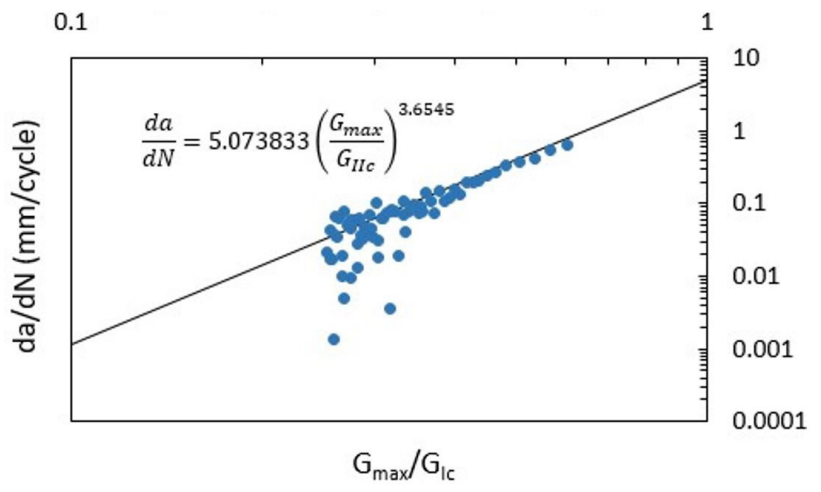

Figure 12. Representative ENF fatigue crack growth curve for $80 \%$ maximum load.

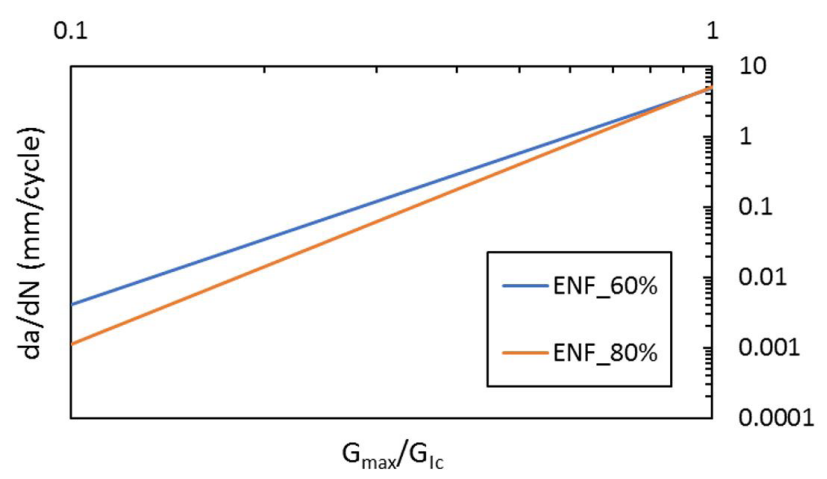

Figure 13. ENF Paris law trends plotted in the same graph. tests, shows high standard deviation which is to be expected given the nature of the FCG curves. There was also a clear difference between the $C$ values obtained. This may be explained by a problem that was detected in the pre-cracking stage: cracks did not open to the same extent, which later was a major differentiator in the fatigue testing stage since the time it took to open a visible crack varied greatly from specimen to specimen (even though the rest of the test was more uniform). This led to different PL intercept values for the same type of test. The number of cycles to failure, shown in Figure 14c, follows the same trend seen in the DCB tests, decreasing with increasing loads, which is expected. In Figure $14 \mathrm{~d}$, it is seen that the threshold energy release rate increases with the load increase due to the energy release rate being directly related to the load applied, following the Irwin-Keys equation.

Comparing the DCB tests to the ENF tests, two main aspects stand out. Firstly, the PL slope is higher in the DCB tests, which happens because adhesives perform better when loaded in shear, with the application of opening forces leading to the adhesive failing faster. Secondly, the threshold energy release rate is higher in the ENF tests. Adhesives are known to be more susceptible to damage under mode I than mode II and the literature corroborates a)
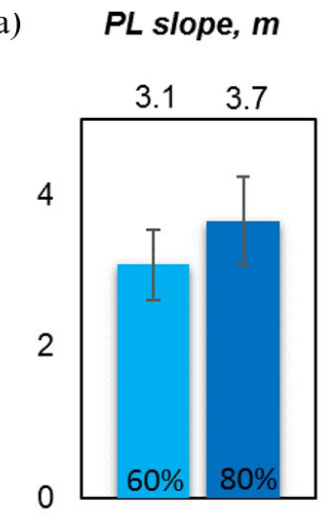

c)

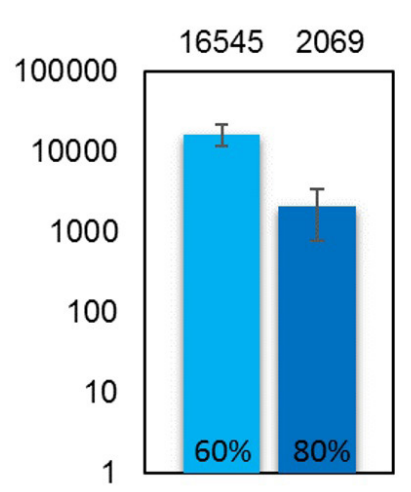

b) PL-intercept, $C$

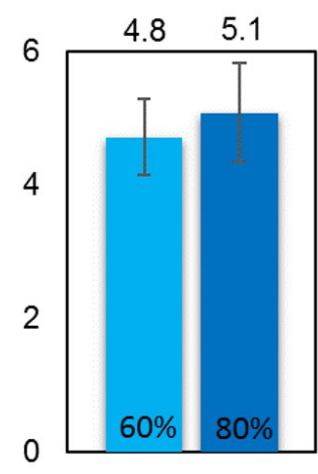

d)

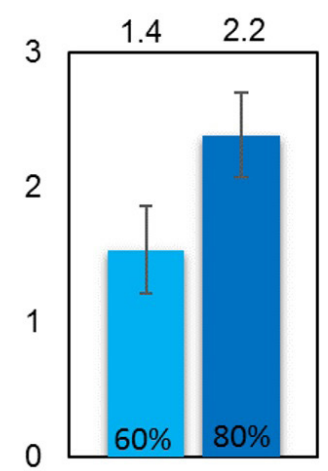

Figure 14. Fatigue results for mode II, ENF tests, (a) Paris law slope results, (b) Paris law y-intercept results, (c) cycles to failure results, (d) $G_{t h}$ results. 
this, stating that more energy is required for a crack surface to appear in mode II than in mode I [26].

\subsubsection{Mixed-mode}

The mixed-mode fatigue analysis was performed for the same phase angles used in the quasi-static tests, for a $\varphi$ of $22.2^{\circ}$ and $56.6^{\circ}$. The measurements were carried out the same way as for quasi-static conditions, two LVDTs measured the top and bottom adherend's arm displacement $\delta_{1}$ and $\delta_{2}$, and the load $P$, was registered by the universal test machine throughout each test. CBBM was used to provide values for both equivalent crack lengths $a_{\text {eqI }}$ and $a_{\text {eqII }}$, and the energy release rate values correspondent of each mode $G_{I}$ and $G_{I I}$.

The initial plan was to perform fatigue tests solely at $80 \%$ of the maximum quasi-static failure load but, as for pure mode fatigue tests, the specimens tested were failing at very low cycles, the load was thus lowered to $60 \%$ of the maximum quasi-static load in hopes to better capture the stable crack propagation. The FCG curves displayed below are characteristic curves for specimens loaded at $60 \%$ and $80 \%$ of the quasi-static failure load obtained for each mode.

\subsubsection{Mixed-mode $\left(\varphi=22.2^{\circ}\right)$}

Following the procedure described above, which was similar to the static testing, the FCG curves for $\phi=22.2^{\circ}$ are displayed in Figure 15. The $x$ axis of this curves was generated by dividing the maximum fracture toughness in each mode during the test phase by the critical fracture toughness under the corresponding mode.

The resulting values for the fatigue testing are shown in Figure 16. Table 6 shows the total PL slope, obtained with Equation (1) which is between the pure mode I and pure mode II results. Considering the literature, the results are within the expected values because similar PL slope values have been obtained for phase angles near $22.2^{\circ}$ [27-29].

a)

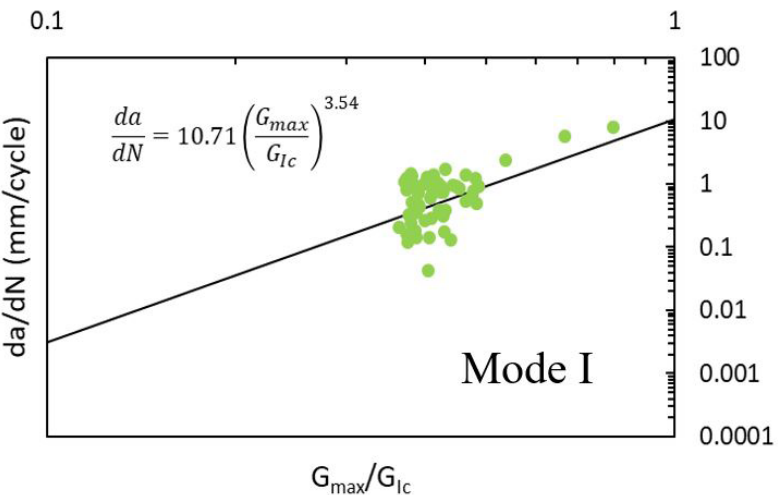

Figure $16 \mathrm{~b}$ shows the PL intercept results where significant dispersion and different mean values for each condition can be seen, which is also explained by the difference in crack size, stemming from the difficult to control pre-cracking stage.

As seen in Figure 16c, the cycles to failure follow the same trend noticed in the previously described modes, decreasing with the load increase. Figure $16 \mathrm{~d}$ shows the threshold energy release rate values, where the mode I component is higher than the mode II. The higher threshold energy release rate for mode $I$ is expectable since for this mixed-mode angle the load is mainly in mode I, a trend also seen under static testing. The load increase also led to an increase in the threshold energy release rate.

\subsubsection{Mixed-mode $\left(\varphi=56.6^{\circ}\right)$}

After submitting specimens to the fatigue loading with $\phi=56.6^{\circ}$, the FCG curves shown in Figure 17 were obtained.

The resulting values for the tested conditions are plotted in Figure 17. As seen in Figure 18a, the PL slope does not appear to be influenced by the load percentage, the values of which are summarized in Table 7.

As shown in Figure 18b, the PL intercept values tend to vary with each condition. The PL intercept variation is expected due to the discrepancy of $C$ at the moment of crack initiation, which is dependent on the size of the pre-crack. The number of cycles to failure are shown in Figure 18c, the expected trend was seen where the number of cycles endured by the specimens decreases with the load increase. The threshold energy release rates, shown in Figure 18d, were higher for mode II than for mode I, which is expected since the energy necessary to open new crack surface for this phase angle is higher in mode II than it is in mode I. The effect of the load increase, however, was less noticeable than for the other tested angles. The effect of load was less noticeable, which might be due to the apparatus' structure which, for this given angle, might partially dampen the cyclic load transmitted to the specimens.

b)

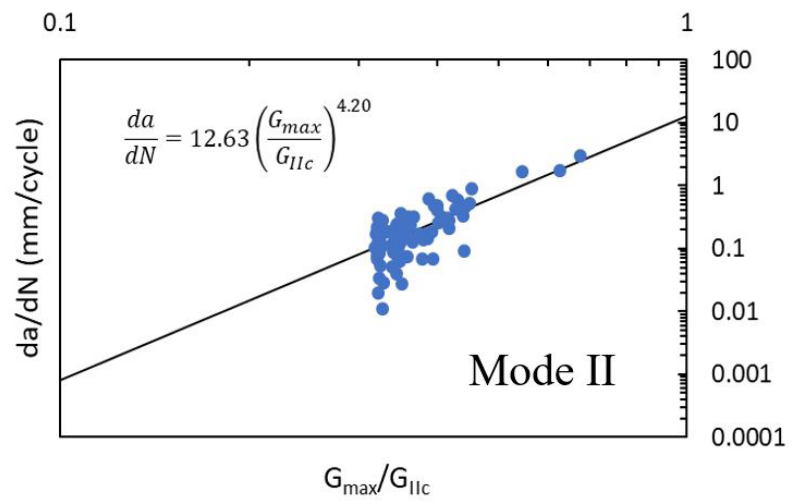

Figure 15. Resulting FCG curves for a phase angle of $22.2^{\circ}$ : (a) mode I component, (b) mode II component. 
a)

PL slope

$m_{l}$

$m_{I I}$

$4.2 \quad 4.6$

4
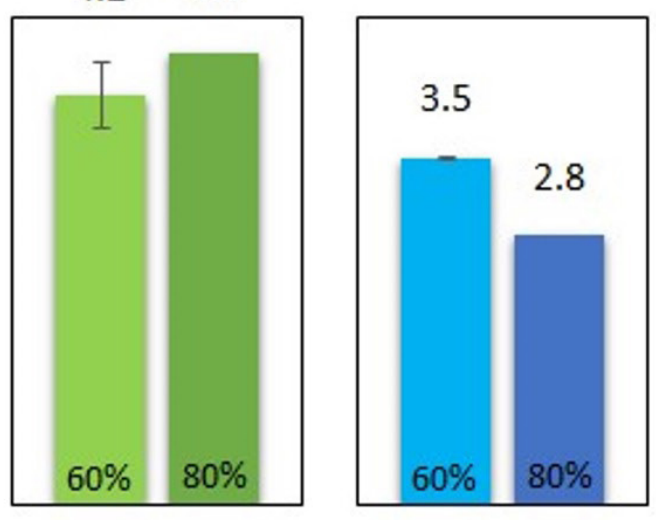

c)
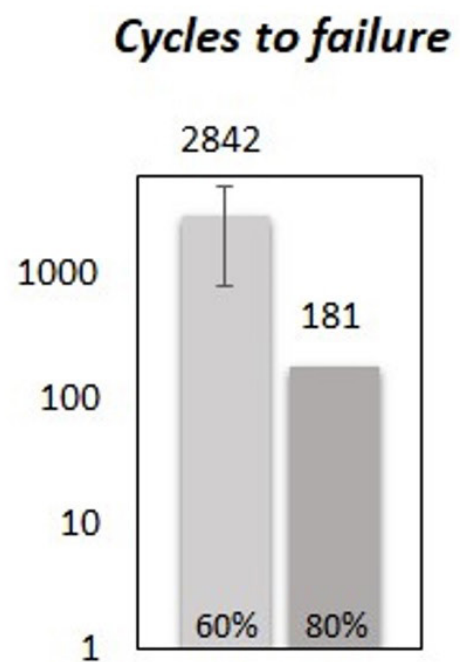

b)

PL intercept

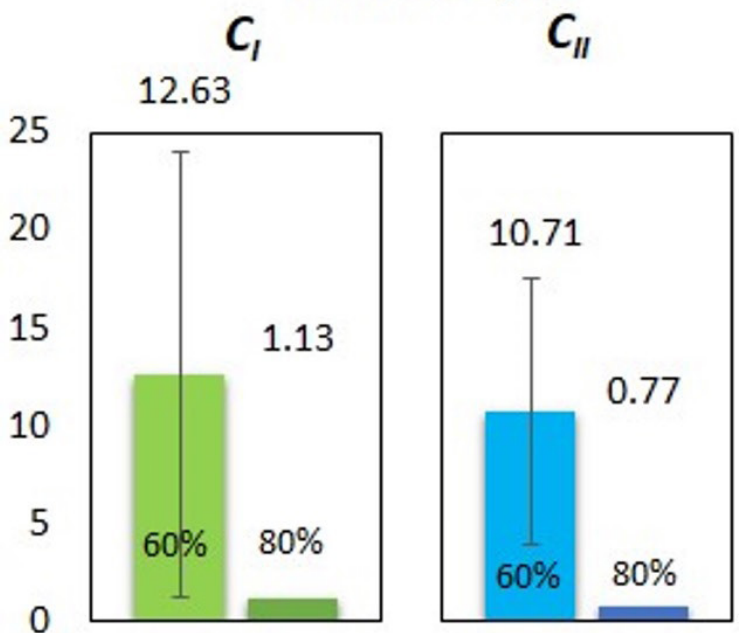

d)

G threshold

$(\mathrm{N} / \mathrm{mm})$

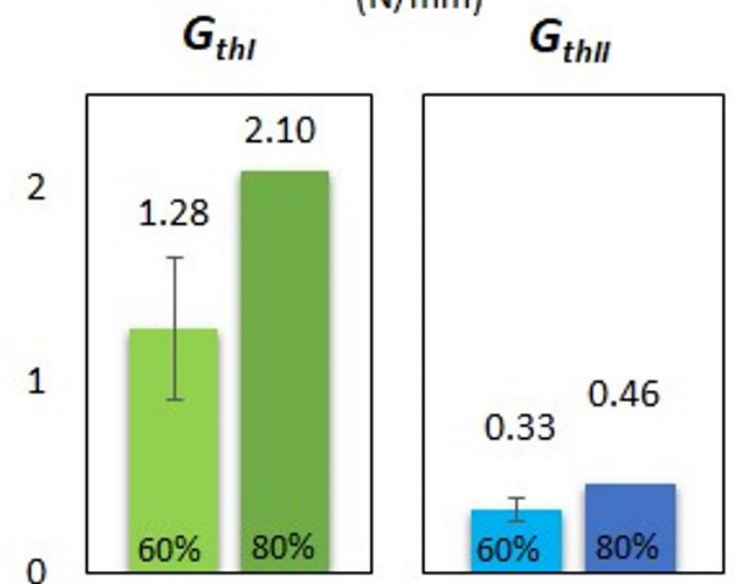

Figure 16. Fatigue results for $\phi=22.2^{\circ}$ : (a) Paris law slope results, (b) Paris law intercept results, (c) cycles to failure results, (d) threshold energy release rate results.

Table 6. Paris law slope for $\phi=22.2^{\circ}$

\begin{tabular}{ccccc}
\hline papparatus $\left({ }^{\circ}\right)$ & $\boldsymbol{m}_{\boldsymbol{I}}$ & $\boldsymbol{m}_{I I}$ & $\boldsymbol{m}_{T}$ & Load (\%) \\
\hline \multirow{2}{*}{22.2} & $4.20 \pm 0.34$ & $3.54 \pm 0.01$ & $5.50 \pm 0.25$ & 60 \\
& 4.62 & 2.76 & 5.38 & 80 \\
\hline
\end{tabular}

\subsection{Paris law envelopes}

The PL slope envelope displayed in Figure 19 was constructed using fatigue data obtained from each pure mode test and from the mixed-mode tests. It can be seen that the pure modes (I and II) display the highest and lowest slopes, respectively, while the mixed-mode slopes are situated between these values. It is noticeable that the existence of mode II type loads influences the fatigue behaviour greatly, as for $\phi=22.2^{\circ}$, not only the mode II PL slope has a considerable value but mode I also decreases considerably when compared to the pure mode I results. The envelope was constructed with a power law to fit the points. The envelope can eventually be improved if more phase angles are tested.

An envelope for the threshold energy release rate, displayed in Figure 20, was obtained using a quadratic fit. It is interesting to notice that a similar trend was detected for static testing, where an increase near mode I was followed by a decrease until pure mode II, which is the highest value in both cases.

Figure 21 shows both envelopes plotted together. A clear difference between mode I and mode II is evident, where the $G_{t h}$ value and the critical energy release rate value seem to distance themselves as the mixed-mode phase angle increases.

\subsection{Parameters as function of phase angle}

To further understand how the phase angle affects adhesive behaviour, test results were plotted as function of 
a)

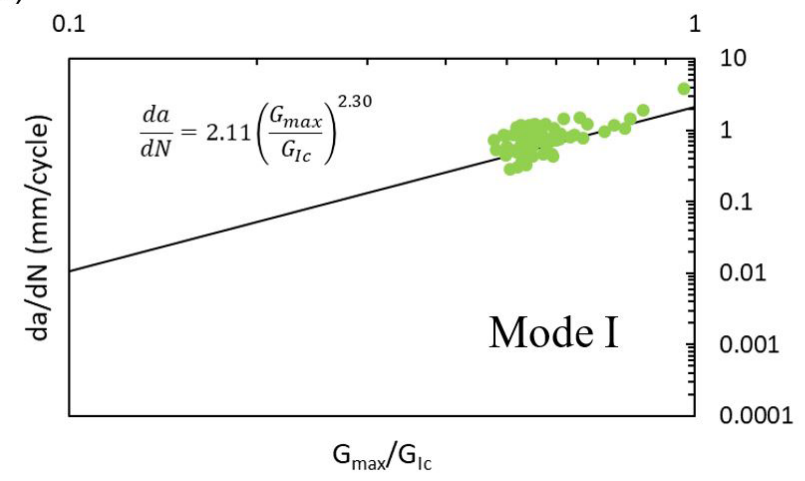

b)

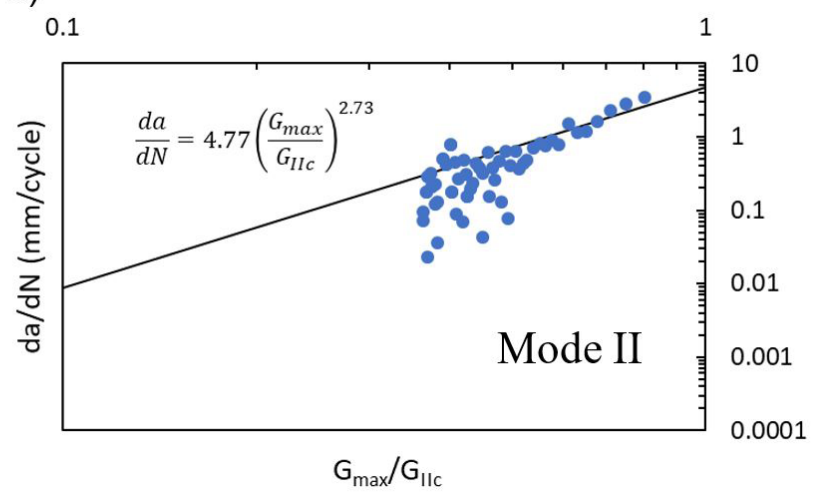

Figure 17. Resulting FCG curves for a phase angle of $56.6^{\circ}$ :, (a) mode I component, (b) mode II component.

a)

PL slope

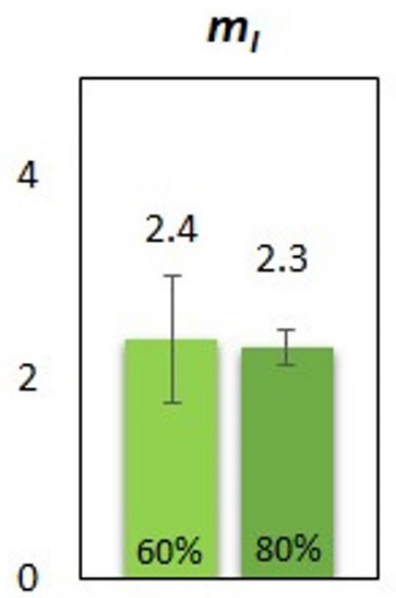

b)

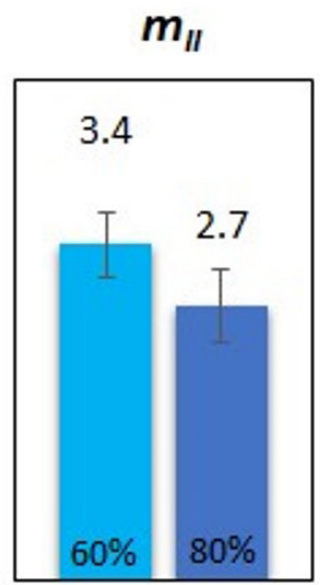

d)

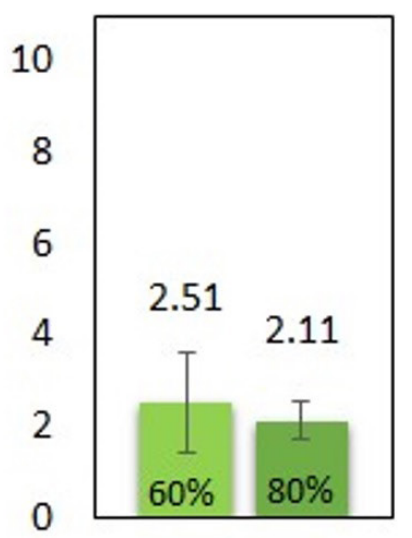

$P L$ intercept

$C_{l}$

8.67

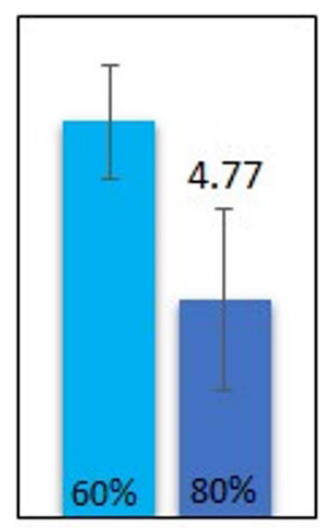

c)
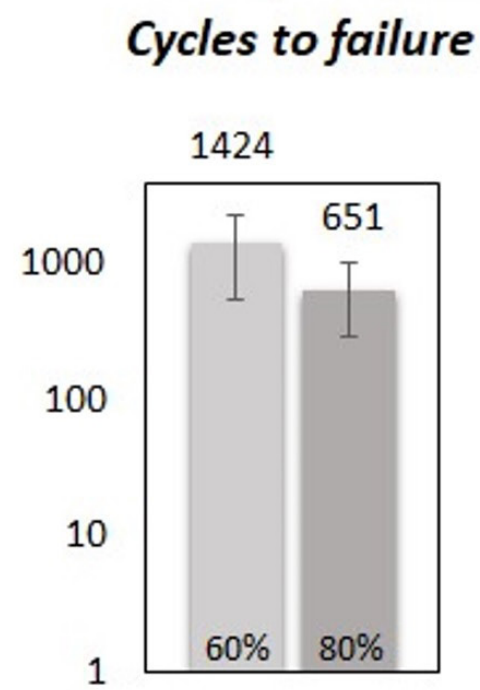

\section{G threshold}

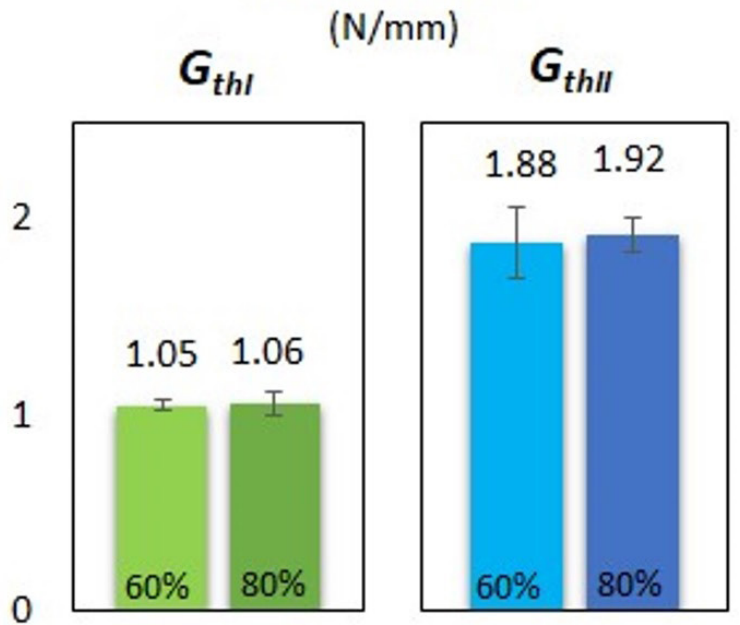

Figure 18. Fatigue results for $\phi=56.6^{\circ}$ : (a) Paris law slope results, (b) Paris law intercept results, (c) cycles to failure results, (d) threshold energy release rate results. 
Table 7. Total Paris law slope for $\phi=56.6^{\circ}$

\begin{tabular}{ccccc}
\hline papparatus $\left({ }^{\circ}\right)$ & $m_{I}$ & $m_{I I}$ & $m_{T}$ & Load (\%) \\
\hline \multirow{2}{*}{56.6} & $2.38 \pm 0.64$ & $3.35 \pm 0.32$ & $4.16 \pm 0.32$ & 60 \\
& $2.30 \pm 0.18$ & $2.73 \pm 0.37$ & $3.58 \pm 0.32$ & 80 \\
\hline
\end{tabular}

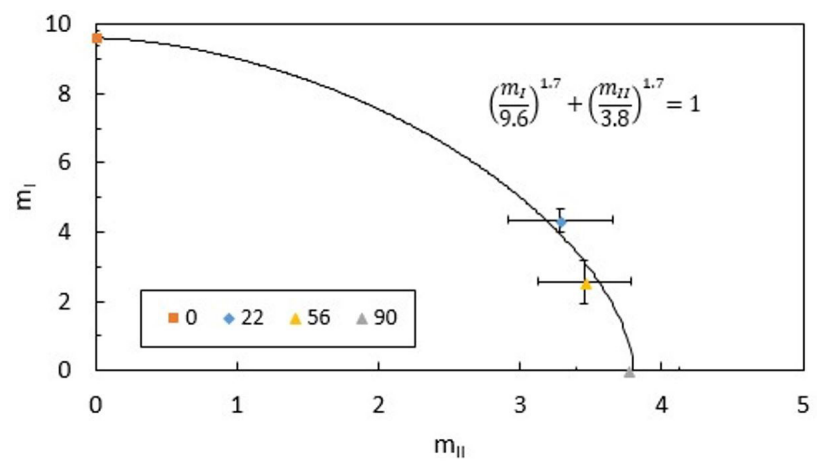

Figure 19. Paris Law slope envelope.

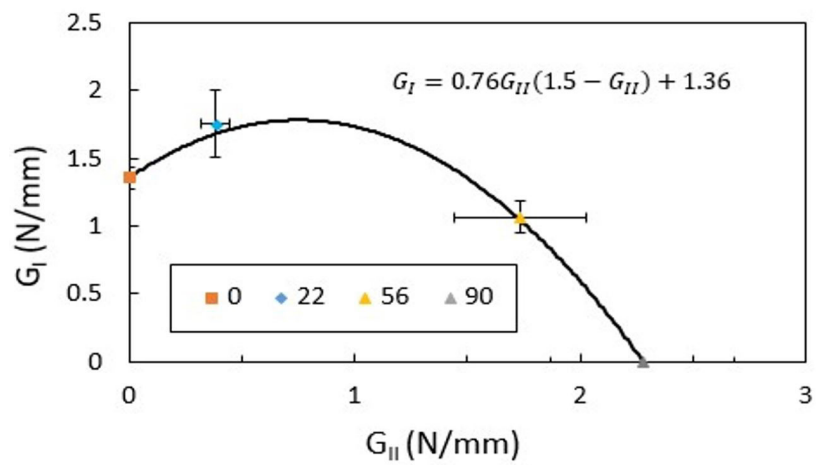

Figure 20. Threshold energy release rate envelope.

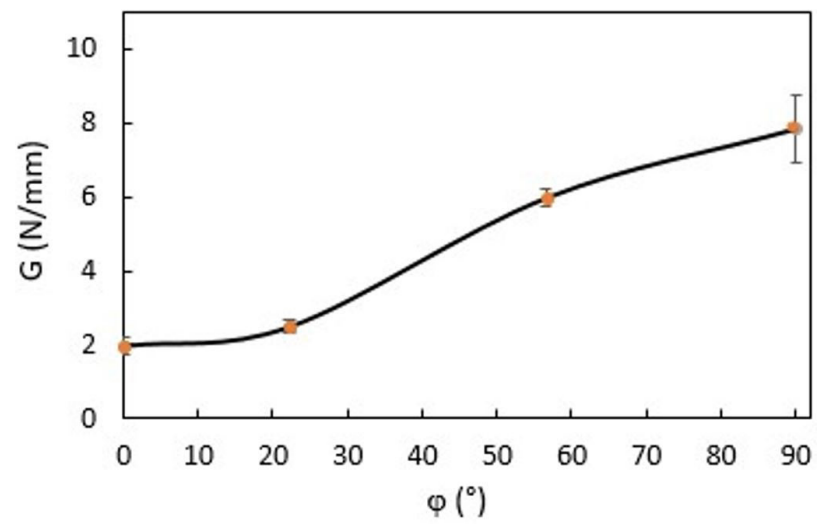

Figure 22. Total fracture energy as function of the phase angle.

the phase angle. Figure 22 displays the total energy release rate, as function of the phase angle.

The structural epoxy adhesive shows the lowest fracture energy in Mode I, as described in the literature [1]. A close relationship between phase angle and fracture energy was found: as the phase angle increases, the mode II component increases and consequently, the fracture energy

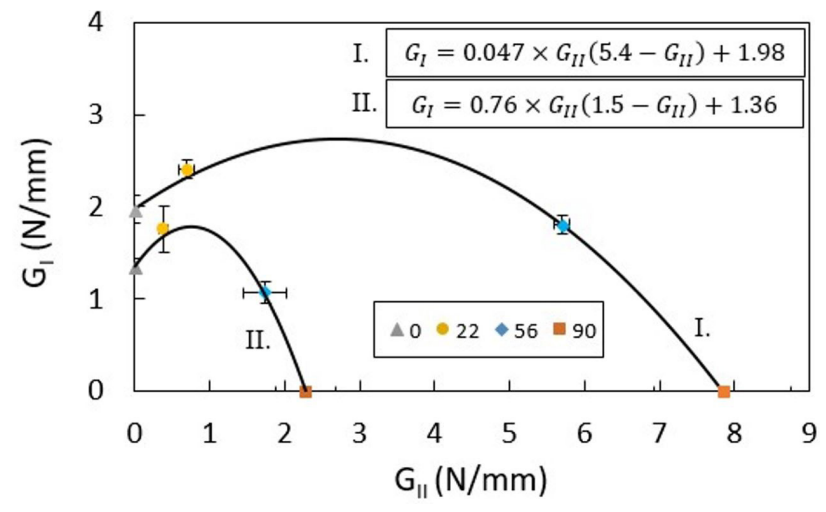

Figure 21. Energy release rate envelope plotted with static loads (I.) and plotted with fatigue loads (II.), both fitted with the quadratic criterion.

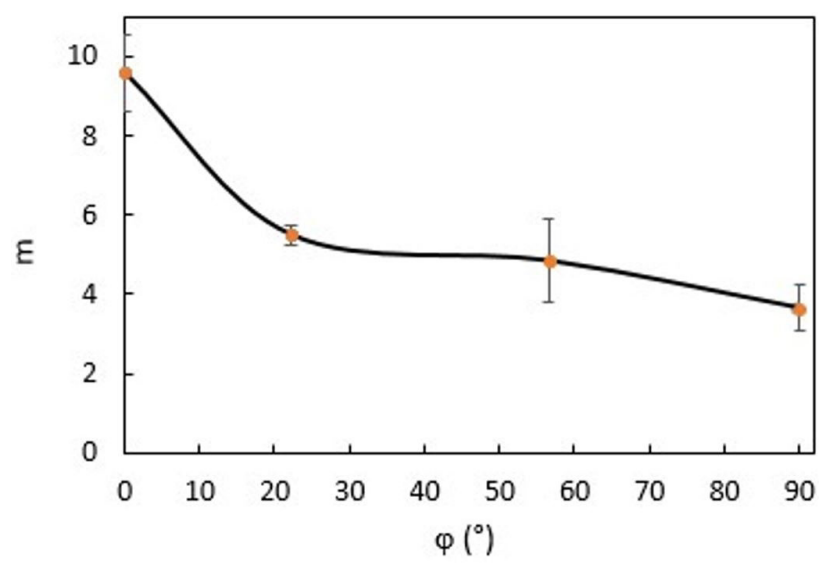

Figure 23. Paris law slope as a function of the mixed-mode phase angle.

increases. This fracture energy increase as a function of phase angle is expected, having already been demonstrated by Costa et al. [24], which obtained similar results for a set of three tested epoxy adhesives. Figure 23 shows the total PL slope, as a function of the phase angle.

The total PL slope decreases as the phase angle increases. Thus, these results allow concluding that the presence of mode II loads delays crack propagation as opposed to loads closer to mode I. This slow decrease in the PL is in agreement with the energy release rate results, which follows an opposite trend. As more energy is needed to form fracture surface, the PL slope tends to decrease. Similar results were obtained by Férnandez et al. [17], who used CFRP specimens in SLB tests to build FCG curves. Férnandez obtained a higher slope for mode I, while for a mixed-mode phase angle of $40^{\circ}$ and pure mode II the slope was more similar, with the mode II slope being slightly smaller.

\section{Conclusions}

The main objective of this work was to assess the mixed-mode fatigue behaviour of an epoxy structural adhesive. Fracture testing allowed concluding that the energy release rate for the pure modes varied slightly, while the same did 
not occur for mixed-mode conditions. For DCB and ENF tests, the energy release rates decreased around $5 \%$, a value which can be considered as statistically insignificant. Using the data obtained, a fracture envelope was compiled, where an increase near mode I was seen.

The fatigue tests results led to the conclusion that the envelope for the threshold energy release rate is similar to the static envelope, although with smaller values. This fracture envelop similarity is expected since fatigue loading is done at a percentage of the maximum load, registering $G$ values below the critical $G$ values calculated for quasi-static conditions. Testing two different load allowed to determine that increasing the load makes the threshold energy release rate increase, while the opposite trend was seen for the cycles to failure, where the load increase originated a drop in the cycles to failure. The PL slope envelope appears to follow a quadratic trend, where the total PL slope decreases as the presence of mode II increases, suggesting that the presence of mode II loads is a key factor in delaying crack propagation.

\section{Acknowledgements}

The authors would like to thank the Portuguese Foundation for Science and Technology (FCT) for supporting the individual grant SFRH/BPD/96992/2013. The authors gratefully acknowledge the funding provided by Project No 29839 POCI-01-0145-FEDER-028473 "Fracture envelope of adhesives at high strain rates (FEASR) and Project $N^{\circ} 028473$ POCI-01-0145-FEDER-028473 Design methodology for impact resistant bonded multi-material automotive structures (ImpactBondDesign), both funded by NORTE-01-0145-FEDER-000022.

\section{References}

1 da Silva LF, Öchsner A, Adams RD. Handbook of adhesion technology. Heidelberg: Springer International Publishing; 2018.

2 Brussat T, Chiu S, Mostovoy S. Fracture mechanics for structural adhesive bonds. Burbank: Lockheed-California CO; 1977.

3 Voloshin A, Arcan M. Pure shear moduli of unidirectional fibre-reinforced materials (FRM). Fibre Science and Technology. 1980;13(2):125-134.

4 El-Hajjar R, Haj-Ali R. In-plane shear testing of thick-section pultruded FRP composites using a modified Arcan fixture. Composites. Part B, Engineering. 2004;35(5):421-428.

5 Yoon S and Hong C. Modified end notched flexure specimen for mixed mode interlaminar fracture in laminated composites. International Journal of Fracture. 1990;43(1):R3R9.

6 Xiao F, Hui C-Y, Kramer E. Analysis of a mixed mode fracture specimen: the asymmetric double cantilever beam. Journal of Materials Science. 1993;28(20):5620-5629.

7 Park S, Dillard DA. Development of a simple mixed-mode fracture test and the resulting fracture energy envelope for an adhesive bond. International Journal of Fracture. 2007;148(3):261-271.

8 ASTM International. Standard test method for mixed mode I-mode II interlaminar fracture toughness of unidirectional fiber reinforced polymer matrix composites. West Conshohocken: ASTM; 2013.

9 Chaves FJ, da Silva L, De Moura M, Dillard D, Esteves V. Fracture mechanics tests in adhesively bonded joints: a literature review. The Journal of Adhesion. 2014;90(12):955-992.

10 Costa M, Carbas R, Marques E, Viana G, da Silva L. An apparatus for mixed-mode fracture characterization of adhesive joints. Theoretical and Applied Fracture Mechanics. 2017;91:94-102.

11 Fernlund G, Spelt J. Mixed-mode fracture characterization of adhesive joints. Composites Science and Technology. 1994;50(4):441-449.

12 Chaves FJ, de Moura M, da Silva L, Dillard DA. Numerical validation of a crack equivalent method for mixedmode I+ II fracture characterization of bonded joints. Engineering Fracture Mechanics. 2013;107:38-47.

13 da Silva L, Esteves V, Chaves F. Fracture toughness of a structural adhesive under mixed mode loadings. Materialwissenschaft und Werkstofftechnik. 2011;42(5):460-470.

14 Stamoulis G, Carrère N, Cognard J-Y, Davies P, Badulescu C. On the experimental mixed-mode failure of adhesively bonded metallic joints. International Journal of Adhesion and Adhesives. 2014;51:148-158.

15 Chai H. Shear fracture. International Journal of Fracture. 1988;37(2):137-159.

16 Benzeggagh M, Kenane M. Measurement of mixed-mode delamination fracture toughness of unidirectional glass/ epoxy composites with mixed-mode bending apparatus. Composites Science and Technology. 1996;56(4):439-449. 
Fatigue behaviour of an epoxy adhesive under mixed-mode conditions

17 Fernández MVC. Fracture Characterization of Composite Bonded Joints Under Fatigue Loading. [doctor thesis] Porto: Universidade do Porto; 2013.

18 De Goeij W, Van Tooren M, Beukers A. Composite adhesive joints under cyclic loading. Materials \& Design. 1999;20(5):213-221.

19 Jablonski D. Fatigue crack growth in structural adhesives. The Journal of Adhesion. 1980;11(2):125-143.

20 ASTM E647-15e1, Standard Test Method for Measurement of Fatigue Crack Growth Rates, ASTM International, West Conshohocken, PA, 2015.

21 Yoder G, Cooley L, Crooker T. Procedures for precision measurement of fatigue crack growth rate using crackopening displacement techniques. In: ASTM International. Fatigue crack growth measurement and data analysis. West Conshohocken: ASTM International; 1981.

22 ASTM International. Standard test method for fracture strength in cleavage of adhesives in bonded joints. West Conshohocken: ASTM; 2004 NF T 76-142. Méthode de préparation de plaques d'adhésifs structuraux pour la réalisation d'éprouvettes d'essai de caractérisation. 1988.

23 ASTM D638-14, Standard Test Method for Tensile Properties of Plastics, ASTM International, West Conshohocken, PA, 2014.

24 Costa M, Carbas R, Benedita M, Marques E, Viana G, da Silva LFM, et al. Static assessment of the mixed-mode behaviour of three epoxy adhesives. Engineering Fracture Mechanics. 2017;182:552-565.

25 Azari S, Jhin G, Papini M, Spelt J. Fatigue threshold and crack growth rate of adhesively bonded joints as a function of load/displacement ratio. Composites. Part A, Applied Science and Manufacturing. 2014;57:59-66.

26 Azari S, Papini M, Schroeder J, Spelt J. Fatigue threshold behavior of adhesive joints. International Journal of Adhesion and Adhesives. 2010;30(3):145-159.

27 Pirondi A, Nicoletto G. Mixed mode I/II fatigue crack growth in adhesive joints. Engineering Fracture Mechanics. 2006;73(16):2557-2568.

28 Hafiz T, Abdel-Wahab M, Crocombe A, Smith P. Mixed-mode fatigue crack growth in FM73 bonded joints. International Journal of Adhesion and Adhesives. 2013;40:188-196.

29 Azari S, Papini M, Schroeder J, Spelt J. The effect of mode ratio and bond interface on the fatigue behavior of a highly-toughened epoxy. Engineering Fracture Mechanics. 2010;77(3):395-414.

Received: 18 Aug. 2020

Accepted: 16 Sep. 2020 